\title{
FORMULASI PASTA GIGI BERBAHAN AKTIF EKSTRAK DAUN SIRIH HITAM SEBAGAI ANTIMIKROBA PENYEBAB RADANG GUSI (GINGIVITIS) DAN GIGI BERLUBANG (CARIES)
}

\author{
Fajar Prasetya \\ Fakultas Farmasi, Universitas Mulawarman
}

\begin{abstract}
This study aims to obtain a formula toothpaste preparations with active ingredient is extracts of black betel leaf which effectively kills microbes cause inflammation of the gums (gingivitis) and tooth perforated (caries). The active ingredient is obtained by performing maceration followed by fractionation of the extract. Test of antimicrobial activity against microorganisms Streptococcus mutans \& Candida albicans using the diffusion method, which will get an effective concentration to be used for toothpaste formulations with active ingredient is black betel leaf. Then continued with the test and evaluation of the effectiveness of the final dosage form of toothpaste preparations. Obtained from the test concentration of $20 \%$-hexane extract fraction of black betel leaf have the greatest antimicrobial power against Streptococcus mutans and Candida albicans. And after optimization of the base, obtained the good mass forming of toothpaste with base PGA (Pulvis Gummi Arabica) at concentration of $30 \%$.
\end{abstract}

Key words: antimicrobial activity, tooth paste, black betel leaf, formulations

\begin{abstract}
ABSTRAK
Penelitian ini bertujuan untuk memperoleh formula sediaan pasta gigi berbahan aktif ekstrak sirih hitam yang efektif membunuh mikroba penyebab radang gusi (gingivitis) dan gigi berlubang (caries). Bahan aktif diperoleh dengan cara melakukan maserasi yang dilanjutkan dengan fraksinasi dari ekstrak tersebut. Uji aktivitas antimikroba terhadap mikroorganisme Streptococcus mutans \& Candida albican menggunakan metode difusi, yang mana akan didapatkan konsentrasi efektif yang akan digunakan untuk formulasi pasta gigi berbahan aktif sirih hitam. Dilanjutkan dengan uji efektivitas dan evaluasi sediaan akhir berupa sediaan pasta gigi. Dari pengujian tersebut diperoleh konsentrasi 20\% ekstrak fraksi n-heksana daun sirih hitam mempunyai daya antimikroba paling besar terhadap Streptococcus mutans dan Candida albican. Dan setelah dilakukan optimasi basis, didapatkan penggunaan basis PGA (Pulvis Gummi Arabica) pada konsentrasi 30\% membentuk massa pasta gigi yang baik.
\end{abstract}

Kata kunci: aktivitas antimikroba, pasta gigi, daun sirih hitam, formulasi

\section{PENDAHULUAN}

Kesehatan mulut merupakan suatu hal penting bagi manusia terutama dalam pergaulan sehari-hari. Masalah kesehatan mulut yang sering dihadapi adalah keluhan sakit gigi yang disebabkan karies gigi dan penyakit jaringan pendukung gigi. Penyakit ini akan menimbulkan plak pada permukaan gigi sehingga gigi berlubang.

Penyakit karies gigi dan penyakit periodontal umumnya hampir dialami 
seluruh penduduk di dunia. Karies gigi dan penyakit periodental umumnya disebabkan oleh kebersihan mulut yang buruk, sehingga terjadi akumulasi plak yang mengandung berbagai macam bakteri. Selain itu plak juga merupakan penyebab utama keradangan. Kondisi ini menunjukkan bahwa penyakit gigi walaupun tidak menimbulkan kematian, tetapi dapat menurunkan produktivitas kerja. (Tjahja, 2007).

Hasil Laporan Riset Kesehatan Dasar tahun 2007 menunjukkan prevalensi masalah gigi dan mulut tiap provinsi di Indonesia, yaitu lima provinsi dengan prevalensi masalah gigi dan mulut tertinggi adalah Gorontalo $33,1 \%$, Sulawesi Tengah 31,2\%, Aceh $30,5 \%$, Sulawesi Utara 29,8\%, dan Kalimantan Selatan 29,2\% sedangkan Kalimantan Timur menduduki peringkat ke 24 dari 33 provinsi dengan angka kejadian sebesar 21,6\%. Hal ini mengindikasikan masih rendahnya tingkat kesadaran masyarakat terhadap kesehatan gigi (Depkes RI, 2008). Sedangkan untuk masalah karies gigi, dilaporkan bahwa karies gigi menyerang kurang lebih $72,1 \%$ penduduk Indonesia. Menurut provinsi, prevalensi karies aktif tertinggi (lebih dari $50 \%$ ) dilaporkan di Kalimantan Barat dan Sulawesi Utara 57,2\%, Jambi 56,1\%, Lampung 54,9\%, Maluku 54,4\%, Yogyakarta 52,3\%, Kalimatan Timur $50,6 \%$, dan Sulawesi Selatan 50,4\%.

Seiring dengan kemajuan teknologi sekarang telah beredar berbagai macam produk pembersih gigi (pasta gigi). Umumnya produk pasta gigi banyak mengandung flour sebagai unsur yang digunakan untuk memperkuat gigi dan menjadikan gigi lebih putih tetapi unsur ini dapat menyebabkan flourosis email pada kadar yang berlebihan serta tidak dapat membunuh bakteri gigi secara efektif.
Untuk mengatasi hal tersebut, diperlukan bahan alami sebagai bahan alternatif pembuatan pasta gigi yang mampu memperkuat gigi dan membunuh bakteri gigi secara efektif. Penggunaan bahan alam memiliki kelebihan karena efek terapeutiknya bersifat konstruktif, efek samping yang ditimbulkan juga sangat kecil sehingga bahan alami relatif lebih aman daripada bahan kimiawi (Hembing, 1998). Berdasarkan hal tersebut, maka diperlukan suatu terobosan baru untuk menghasilkan produk pasta gigi berbahan alami sebagai produk yang sudah ada dengan tanpa mengurangi kualitasnya.

Salah satu tumbuhan asli Indonesia yang dapat berfungsi sebagai obat tradisional adalah sirih hitam. Sirih hitam merupakan salah satu spesies dari tanaman sirih yang banyak terdapat di Indonesia. Spesies lainnya dari tanaman ini, yaitu sirih merah, sering digunakan masyarakat Indonesia untuk berbagai pengobatan, salah satunya adalah untuk penyakit mulut seperti gingivitis dan karies gigi yang disebabkan oleh bakteri. Bakteri yang dominan menyebabkan berbagai penyakit mulut adalah spesies Actinomyces, Streptococcus, Fusobacterium nucleatum, Bacteroides intermedius, dan berbagai variasi spesies Bacteroides yang tidak berpigmen (Manson, 1993).

Berbagai teori mengatakan bahwa tumbuhan yang berasal dari spesies yang sama kemungkinan juga memiliki kandungan metabolit yang sama. Melalui informasi tersebut dan setelah dilakukan uji fitokimia, daun sirih hitam terbukti mengandung senyawa alkaloid, karatenoid, senyawa fenolik, flavanoid, saponin, tanin, steroid, dan triterpenoid. 
Formulasi Pasta Gigi Berbahan Aktif Ekstrak Daun Sirih Hitam Sebagai Antimikroba Penyebab Radang Gusi (Gingivitis) Dan Gigi Berlubang (Caries)

Senyawa kimia yang berfungsi sebagai antimikroba dalam hal ini adalah tanin, senyawa fenolik, saponin, flavanoid, alkaloid, dan steroid (Lemmens, 1999). Antimikroba adalah senyawa yang dapat menghambat atau membunuh mikroorganisme hidup. Setelah dilakukan uji antimikroba, ekstrak daun sirih hitam terbukti mempunyai kemampuan dalam menghambat pertumbuhan mikroba uji Streptococcus mutans, Staphylococcus aureus, Candida albicans dan Candida utilis.

Berdasarkan hasil yang didapat dari skrining fitokimia dan uji antimikroba tersebut, serta tujuan ingin meningkatkan efisiensi juga kenyamanan dalam pemakaian ekstrak, penulis ingin melakukan formulasi ekstrak daun sirih hitam ke dalam sediaan pasta gigi, sehingga dapat menjadi produk alternatif dalam mengatasi permasalahan radang gusi (gingivitis) dan gigi berlubang (caries).

\section{METODE}

Berikut merupakan metode yang digunakan dalam penelitian:

1. Mendapatkan bahan aktif yang berupa ekstrak dengan cara maserasi yang dilanjutkan dengan fraksinasi.

2. Identifikasi metabolit sekunder ekstrak kasar dan variasi fraksi dengan standar prosedur (Trease, 1989).

3. Uji aktivitas antimikroba terhadap mikroorganisme Streptococcus mutans \& Candida albican menggunakan metode difusi, yang mana akan didapatkan konsentrasi efektif yang akan digunakan untuk formulasi pasta gigi berbahan aktif sirih hitam.

4. Optimasi basis pasta gigi dengan variasi komposisi dengan menggunakan basis PGA (Pulvis Gummi Arabica)
5. Formulasi pasta gigi dengan variasi konsentrasi ekstrak dengan menggunakan eksipien/zat tambahan yang kompatibel dengan zat aktif berdasarkan studi literatur.

\section{Pelaksanaan}

Penelitian ini dilaksanakan pada bulan Februari hingga Mei 2011. Rincian waktu kegiatan penelitian diantaranya adalah sebagai berikut :

1. Pembelian sampel segar di Jalan Cipto Mangunkusumo Samarinda Seberang pada tanggal 23 Februari 2011.

2. Ekstraksi sampel menggunakan metode maserasi di Laboratorium Kimia Bahan Alam Farmasi Universitas Mulawarman pada tanggal 29 Februari - 30 Maret 2011.

3. Fraksinasi ekstrak kasar etanol sampel dengan berbagai pelarut di Laboratorium Kimia Bahan Alam Farmasi Universitas Mulawarman pada tanggal 21 - 22 April 2011.

4. Identifikasi metabolit sekunder ekstrak sampel dengan variasi fraksi di Laboratorium Kimia Bahan Alam Farmasi Universitas Mulawarman pada tanggal 28 - 29 April 2011.

5. Uji aktivitas antimikroba terhadap mikroorganisme Streptococcus mutans dan Candida albican di Laboratorium Biologi Farmasi Universitas Mulawarman pada tanggal 30 April 30 Mei 2011.

6. Optimasi basis pasta gigi dengan variasi komposisi di Laboratorium Farmasetika Farmasi Universitas Mulawarman pada tanggal 26-28 Mei 2011. 
Formulasi Pasta Gigi Berbahan Aktif Ekstrak Daun Sirih Hitam Sebagai Antimikroba Penyebab Radang Gusi (Gingivitis) Dan Gigi Berlubang (Caries)

\section{Peralatan Penelitian.}

Peralatan yang digunakan dalam penelitian ini adalah seperangkat alat maserasi, rotary evaporator, timbangan digital, pipet tetes, labu erlenmeyer, stirrer, kertas saring, gelas ukur, labu ukur, corong, botol kaca, waterbatch, aluminium foil, cawan porselin, batang pengaduk, tabung reaksi, rak tabung reaksi, botol selai, desikator vakum, cawan petri, paper disk, inkubator, kertas saring, laminar air flow, lumpang dan alu, mikrometer skrup, tube.

\section{HASIL DAN PEMBAHASAN}

Formula pasta gigi merupakan sediaan yang tersusun atas agen polishing (penggosok), agen moistener (pelembab), agen deterjen dan foaming (pembuat busa), agen pengikat, pemanis, flavour (pemberi rasa), dan pengawet yang dipadukan dengan bahan aktif dari ekstrak daun sirih hitam yang bertujuan sebagai sediaan antimikroba penyebab radang gusi (gingivitis) dan gigi berlubang (caries).

Formulasi sediaan pasta gigi berbahan aktif ekstrak daun sirih hitam dimulai dari pengolahan bahan aktif yaitu sirih hitam segar dengan menggunakan metode maserasi. Dimana, pada penelitian ini pembuatan ekstrak daun sirih hitam dilakukan dengan cara direndam dengan menggunakan pelarut organik (etanol) selama 2 x 24 jam. Setelah didapatkan ekstrak kasar etanol daun sirih hitam kemudian dilakukan pengelompokan senyawa berdasarkan tingkat kepolaran. Pelarut yang digunakan yaitu $n$-heksana, etil asetat, dan n-butanol. Tetapi dikarenakan ekstrak yang didapatkan dari fraksi $n$-butanol tidak mencukupi untuk pengujian, maka fraksi yang digunakan hanya fraksi $n$-heksana dan fraksi etil asetat.

Sebelum melakukan pembuatan sediaan pasta gigi, dilakukan terlebih dahulu identifikasi metabolit sekunder dari ekstrak kasar dan fraksi daun sirih hitam, identifikasi metabolit sekunder dilakukan untuk mengetahui kandungan golongan senyawa yang terkandung dalam ekstrak pekat dan fraksi-fraksi tersebut. Hasil uji metabolit sekunder dapat dilihat pada Tabel 1.

Tabel 1. Hasil Uji Golongan Metabolit Sekunder pada Daun Sirih Hitam

\begin{tabular}{lccc}
\multicolumn{1}{c}{$\begin{array}{c}\text { Golongan Metabolit } \\
\text { Sekunder }\end{array}$} & \multicolumn{3}{c}{ Ekstrak dan Fraksi } \\
\cline { 2 - 4 } & Ekstrak Etanol & $\begin{array}{c}\text { Fraksi } \\
\text { n-Heksan }\end{array}$ & $\begin{array}{c}\text { Fraksi } \\
\text { Etil Asetat }\end{array}$ \\
\hline Alkaloid & + & + & - \\
Flavanoid & + & - & - \\
Saponin & + & + & + \\
Tanin & + & + & + \\
Senyawa Fenol & + & + & + \\
Karatenoid & + & + & + \\
Steroid dan Triterpenoid & + & & \\
San: & & & \\
$=$ Terdeteksi metabolit sekunder & & & \\
Tidak terdeteksi metabolit sekunder & & &
\end{tabular}


Formulasi Pasta Gigi Berbahan Aktif Ekstrak Daun Sirih Hitam Sebagai Antimikroba Penyebab Radang Gusi (Gingivitis) Dan Gigi Berlubang (Caries)

Setelah dilakukan identifikasi metabolit sekunder maka dilakukan pengujian antimikroba menggunakan mikroba uji Streptococcus mutans dan Candida albican. Kedua mikroba ini diplih karena kedua mikroba tersebut merupakan mikroba yang dominan menyebabkan penyakit mulut. Pada awalnya dilakukan skrining awal uji antimikroba untuk mengetahui ekstrak mana yang paling efektif dalam membunuh mikroba. Metode paper disc yang digunakan berdasarkan kemampuan penetrasi bahan uji ke dalam media pertumbuhan mikroba secara difusi sehingga menghasilkan pengaruh daya hambat berupa daerah hambatan berbentuk lingkaran yang diukur diameternya sesuai kekuatan antimikroba dari bahan yang diuji. Hasil skrining awal uji antimikroba dapat dilihat pada Tabel 2 .

Tabel 2. Hasil skrining awal antimikroba dari ekstrak dan beberapa fraksi

- Ekstrak kasar etanol

\begin{tabular}{cccc}
\hline \multirow{2}{*}{ Konsentrasi $(\%)$} & \multicolumn{2}{c}{ Besar Zona Bunuh $(\mathrm{mm})$} & \multirow{2}{*}{ Rata-rata } \\
\cline { 2 - 3 } & 1 & 2 & - \\
\hline 10 & - & - & - \\
15 & - & - & - \\
20 & - & - & 19,04 \\
25 & 18,98 & 19,10 & \\
\hline
\end{tabular}

- $\quad$ Fraksi n-heksana

\begin{tabular}{cccc}
\hline \multirow{2}{*}{ Konsentrasi $(\%)$} & \multicolumn{2}{c}{ Besar Zona Bunuh $(\mathrm{mm})$} & \multirow{2}{*}{ Rata-rata } \\
\cline { 2 - 3 } & 1 & 2 & \\
\hline 10 & 19,40 & 19,32 & 19,30 \\
15 & 22,10 & 22,08 & 22,09 \\
$\mathbf{2 0}$ & $\mathbf{2 3 , 2 1}$ & $\mathbf{2 3 , 2 7}$ & $\mathbf{2 3 , 2 4}$ \\
25 & 19,08 & 19,18 & 19,13 \\
\hline
\end{tabular}

- $\quad$ Fraksi etil asetat

\begin{tabular}{cccc}
\hline \multirow{2}{*}{ Konsentrasi $(\%)$} & \multicolumn{2}{c}{ Besar Zona Bunuh $(\mathrm{mm})$} & \multirow{2}{*}{ Rata-rata } \\
\cline { 2 - 3 } & 1 & 2 & \\
\hline 10 & 16,92 & 15,85 & 16,38 \\
15 & 16,03 & 16,86 & 16,45 \\
20 & 19,16 & 19,18 & 19,17 \\
25 & 15,30 & 15,12 & 15,21 \\
\hline
\end{tabular}

- Fraksi etanol

\begin{tabular}{cccc}
\hline \multirow{2}{*}{ Konsentrasi (\%) } & \multicolumn{2}{c}{ Besar Zona Bunuh $(\mathrm{mm})$} & \multirow{2}{*}{ Rata-rata } \\
\cline { 2 - 3 } & 1 & 2 & \\
\hline 10 & 17,73 & 17,04 & 17,38 \\
15 & 18,31 & 19,03 & 18,67 \\
20 & 19,28 & 19,27 & 19,27 \\
25 & 18,28 & 19,35 & 18,81 \\
\hline
\end{tabular}


Formulasi Pasta Gigi Berbahan Aktif Ekstrak Daun Sirih Hitam Sebagai Antimikroba Penyebab Radang Gusi (Gingivitis) Dan Gigi Berlubang (Caries)

Dari hasil skrining awal pada ekstrak kasar etanol, fraksi n-heksana, fraksi etil asetat, dan fraksi etanol dapat dilihat pembentukan zona bunuh yang paling baik adalah pada fraksi n-heksana dengan konsentrasi $20 \%$, dimana rata-rata diameter zona bunuh yaitu sebesar 23,24 $\mathrm{mm}$. Sehingga dilakukan pengujian lanjutan dari ekstrak fraksi n-heksana dengan variasi konsentrasi berturut-turut 15\%,17,5\%, $20 \%$, dan $22,5 \%$ untuk mikroba uji Streptococcus mutans dan Candida albican. Hasil pengujian antimikroba pada ekstrak fraksi n-heksana dapat dilihat pada Tabel 3.

Didapatkan hasil aktivitas yang menurun pada uji lanjutan dibandingkan dengan skrining awal, hal ini dimungkinkan karena terjadinya penurunan stabilitas dan aktivitas ekstrak selama penyimpanan.

Formula pasta gigi terdiri atas silika gel sebagai agen polishing (penggosok), gliserin sebagai agen moistener (pelembab), sodium lauril sulfat sebagai agen deterjen dan pembuat busa, PGA (Pulvis Gummi Arabica) sebagai basis pasta gigi, sodium sakarin sebagai pemanis, mentol sebagai pemberi rasa, dan sodium benzoat sebagai pengawet.

Dilakukan optimasi komposisi basis untuk mendapatkan basis pasta gigi yang kompatibel dalam membentuk massa pasta gigi yang baik. Basis yang digunakan dalam formula ini adalah PGA (Pulvis Gummi Arabica). Rancangan formula dapat dilihat pada Tabel 4.

Tabel 3. Hasil uji lanjutan dari fraksi n-heksana terhadap mikroba uji

- Streptococcus mutans

\begin{tabular}{ccccc}
\hline \multirow{2}{*}{$\begin{array}{c}\text { Konsentrasi } \\
(\%)\end{array}$} & \multicolumn{3}{c}{ Besar Zona Bunuh $(\mathrm{mm})$} & \multirow{2}{*}{ Rata-rata } \\
\cline { 2 - 3 } & 1 & 2 & 3 & \\
\hline 15 & 5,85 & 5,41 & 5,38 & 5,55 \\
17,5 & 6,12 & 5,87 & 5,91 & 5,97 \\
20 & 6,28 & 6,54 & 6,17 & 6,33 \\
22,5 & 5,90 & 5,52 & 5,93 & 5,78 \\
\hline
\end{tabular}

- Candida albican

\begin{tabular}{ccccc}
\hline \multirow{2}{*}{$\begin{array}{c}\text { Konsentrasi } \\
(\%)\end{array}$} & \multicolumn{3}{c}{ Besar Zona Bunuh $(\mathrm{mm})$} & \multirow{2}{*}{ Rata-rata } \\
\cline { 2 - 3 } & 1 & 2 & 3 & \\
\hline 15 & 3,77 & 3,74 & 3,69 & 3,73 \\
17,5 & 3,88 & 4,09 & 3,72 & 3,90 \\
20 & 4,14 & 4,23 & 4,35 & 4,24 \\
22,5 & 3,92 & 3,65 & 3,98 & 3,85 \\
\hline
\end{tabular}

Tabel 4. Rancangan Formula Pasta Gigi

\begin{tabular}{lccccc}
\hline \multirow{2}{*}{ Nama Bahan } & \multicolumn{5}{c}{ Konsentrasi (\%) dalam 1 gram sediaan } \\
\cline { 2 - 6 } & F1 & F2 & F3 & F4 & F5 \\
\hline Silika gel & 30 & 30 & 30 & 30 & $\mathbf{3 0}$ \\
Sodium lauril sulfat & 1 & 2 & 2 & 2 & $\mathbf{2}$ \\
Gliserin & 25 & 30 & 30 & 30 & $\mathbf{2 0}$ \\
Mentol & 0,4 & 0,4 & 0,5 & 0,5 & $\mathbf{0 , 5}$ \\
Sodium benzoat & 0,1 & 0,1 & 0,1 & 0,1 & $\mathbf{0 , 1}$ \\
PGA & 10 & 20 & 30 & 30 & $\mathbf{3 0}$ \\
Air & - & - & 10 tetes & - & $\mathbf{1}$ tetes \\
\hline
\end{tabular}


Setelah dilakukan optimasi komposisi basis maka didapatkan formula 5 merupakan formula yang paling baik ditinjau dari tekstur dan penampilan, dimana konsetrasi silika gel yang digunakan adalah $30 \%$, sodium lauril sulfat $2 \%$, sodium sakarin $0,3 \%$, gliserin $20 \%$, mentol $0,5 \%$, sodium benzoat $0,1 \%$, dan PGA $30 \%$.

\section{KESIMPULAN DAN SARAN}

\section{A. Kesimpulan}

1. Ekstrak yang paling efektif dalam membunuh mikroba uji Strepstococcus mutans dan Candida albican adalah fraksi n-heksana dengan konsentrasi $20 \%$.

2. Penggunaan basis PGA (Pulvis Gummi Arabica) yang baik ditinjau dari penampilan dalam membentuk massa pasta gigi yang baik adalah pada konsentrasi $30 \%$.

3. Formula pasta gigi berbahan aktif ekstrak daun sirih hitam yang baik ditinjau dari penampilan dan tekstur adalah silika gel (30\%), sodium lauril sulfat $(2 \%)$, sodium sakarin $(0,3 \%)$, gliserin $(20 \%)$, mentol $(0,5 \%)$, sodium benzoat $(0,1 \%)$, dan PGA $(30 \%)$.

\section{B. Saran}

1. Penelitian lebih lanjut tentang uji efektifitas dan uji stabilitas formula pasta gigi setelah dilakukan penyimpanan.

2. Penelitian lebih lanjut tentang penggunaan ekstrak daun sirih hitam sebagai bahan aktif sediaan pasta gigi yaitu optimasi sediaan yang stabil.

3. Pengkajian mengenai bahan-bahan tambahan yang lebih sesuai dalam formulasi.

4. Penelitian isolasi senyawa aktif daun sirih hitam, agar dapat dikaji perkembangan manfaatnya.

5. Pembudidayaan daun sirih hitam, dikarenakan tanaman ini masih tergolong baru sehingga susah diperoleh.

\section{DAFTAR PUSTAKA}

1. Hembing, W.K. 1998. Tanaman Berkhasiat Obat di Indonesia Jilid Keempat. Penerbit Pustaka Kartini: Jakarta.

2. Lemmens, R.H.M.J. \& N Wulijarni Soejipto.1999. Sumber Daya Nabati Asia Tenggara, No. 3, Tumbuhtumbuhan Penghasil Pewarna dan Tanin. PT. Balai Pustaka: Jakarta.

3. Manson, J.D \& B.M. Eley. 1993. Buku Ajar Periodonti. Alih Bahasa Anastasia S. Hipokrates: Jakarta.

4. Tjahja, Indirawati. 2007. Status Kesehatan Gigi dan Mulut Ditinjau dari Faktor Individu Pengunjung Puskesmas DKI Jakarta Tahun 2007. Pusat Penelitian dan Pengembangan Biomedis: Jakarta.

5. Depkes RI. 2008. Laporan Hasil Riset Kesehatan Dasar (RISKESDAS) Nasional 2007. Badan Penelitian dan Pengembangan Kesehatan: Jakarta. 